\title{
Selbst ist der Mann
}

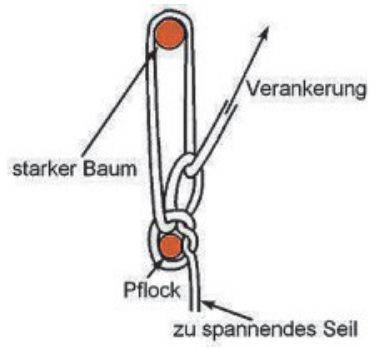

Erhard Taverna
Die Frau war halbseitig gelähmt, am herabhängenden Mundwinkel klebte ein Speichelfaden. Als er kam, war sie bei Bewusstsein und konnte schlucken, doch selbst ihr Mann konnte ihre Worte nicht verstehen. Das kleine Gehöft am Waldrand lag abgelegen und war nur zu Fuss erreichbar. Es hatte ihn einige Anstrengung gekostet, mit seinem Rettungskoffer dorthin zu gelangen. Nicht einmal ein Telefon gab es dort. Der Nachbar hatte stellvertretend angerufen. «Ihre Frau muss sofort in die Klinik», entschied er, «mit dem Allrad ist das kein Problem.» «Nein», war die knappe Antwort, «sie bleibt hier, ich kümmere mich um sie» und dann mit entschlossener Miene, die keinen Widerspruch duldete: «Wir haben noch nie einen Arzt gebraucht.» Ihr Kreislauf war unauffällig, sie atmete normal. Das betagte Paar sah man kaum je im Dorf. Er verschob den angekündeten Transport auf einen nächsten Besuch und schärfte dem Nachbarn ein, beim geringsten Anzeichen einer Verschlechterung unbedingt anzurufen.

Der Zustand der Patientin blieb unverändert. Sie trank, sie lag frisch gewaschen auf ihrem Bett. Eine Einrichtung namens «Stroke Unit» war damals noch unbekannt, sie hätte die beiden kaum umgestimmt. Die Gemeindeschwester brachte einige Hilfsmittel und erteilte ihre guten Ratschläge, die ihr Mann brummend zur Kenntnis nahm. Wie in vielen dieser alten Häuser führte eine schmale Holztreppe neben dem Kachelofen durch eine Bodentüre ins Schlafzimmer. Wenige Tage später hatte er den schmalen Durchlass erweitert und die Treppe durch einen Aufzug ersetzt. Am massiven Schwenkarm in Bettnähe war ein Ohrensessel aufgehängt, in den er behutsam seine Frau setzte. Ein breiter Ledergurt verhinderte, dass sie herausrutschte. Über das dicke Hanfseil, das über zwei hölzerne Umlenkrollen lief, dirigierte er langsam das Gefährt in die Tiefe. Der Sessel wurde ausgeklinkt und liess sich mühelos über die angebrachten Rädchen an das offene Fenster verschieben. Sie hatte keine Schmerzen und schien zufrieden. Eine gerollte Binde beugte die Finger der gelähmten Hand, die bandagierten Unterschenkel und Füsse ruhten bequem auf einem ausklappbaren Trittbrett. Es war absolut sinnlos, auf einer Spitaleinweisung zu bestehen. Auch sie gab deutlich zu erkennen, dass ihr die Obhut im eigenen Haus mehr als genügte. Man nahm seine Besuche hin, sie waren Teil einer unvermeidlichen Routine, die nichts Wesentliches veränderte. Es sei denn, dass sie den Ehemann zu immer weiteren Erfindungen anspornten. Über dem Kuhstall hatte er im Tenn seine kleine Werkstatt ausgebaut. Ausser einer alten Bohrmaschine gab es dort keine elektrisch betreibbaren Geräte. Alles auf der alten
Hobelbank war mit einfachsten Mitteln handgefertigt und entstand direkt aus dem Kopf, das heisst ohne Pläne und Skizzen.

Wochen vergingen und es war Sommer geworden. Doch die Lähmungen blieben. Das Haus verschwand beinahe hinter dem üppigen Laub der nahen Ulmen. Der Mann baute eine Rampe bis zum nahen Holunderstrauch, in dessen Schatten die Frau dem Summen der Bienen und den Vögeln zuhörte. Wenn er sich mit seinem Rucksack entfernte um einzukaufen, wartete sie dort schlafend seine Rückkehr ab. Er versah einen massiven Holzstuhl mit einem Nachtgeschirr für ihre Notdurft, und er bastelte eine Buchstütze, eine Leselampe und einen Klingelzug, der über eine Schnur bis in den Stall mehrere Glöckchen zum Bimmeln brachte. Ihre Abhängigkeit weckte in ihm die bisher verborgenen Talente. Er entwickelte sich zum perfekten Pfleger. Nicht die kleinste Druckstelle war zu entdecken. Er wusch sie sorgfältig von Kopf bis Fuss, reinigte die Wäsche, cremte die Haut, besorgte Zellstoffwindeln und bewegte täglich, gemäss einer bebilderten Anleitung, die Gelenke der gelähmten Köperseite. Im Herbst brachte die selbstgebaute Seilbahn die Frau bergab zur Sitzbank neben der Linde. Sie schwebte an sonnigen Tagen im karabinergesicherten Wäschekorb, schaukelnd über die blühenden Wiesenblumen, bis zur Verankerung am Stamm. Körperlich machte sie nur wenig Fortschritte. Die Abstände zwischen den hausärztlichen Besuchen wurden länger. Die Lindenblüten dufteten, das Laub wurde gelb, die ersten Blätter fielen. Dann starb sie.

Im folgenden Winter erlitt der Mann selber einen Schlaganfall, von dem sich die gelähmte Seite nur unvollständig erholte. Er musste - nun erst recht - Tag und Nacht im Schein einer Petrollampe gearbeitet haben. Es blieb ein Rätsel, wie es ihm gelungen war, die langen Hanfseile ohne fremde Hilfe auszuspannen. Sie verliefen zum Teil meterhoch über der Schneedecke, verbanden über Stützen und dicke Astgabeln Stall und Scheune und reichten bis zum Holzstoss am Rand des steilen Tobels. Das Ganze sah aus wie die heute beliebten Seilparks, die Plattformen von Baum zu Baum miteinander verbinden. Eine dieser Tyroliennefahrten wurde ihm zum Verhängnis. Eine Rücklaufsperre löste sich, eine Verankerung gab nach, eine Stütze knickte ein, wer weiss. Die Traggurten waren intakt, als man einige Tage später den Erfrorenen fand. Vielleicht war er beim Absturz schon tot. Ein weiterer Schlaganfall, ein Herzstillstand. Schliesslich war er schon sehr alt. Und ausser den Krähen, deren krächzende Schwärme dem Nachbarn aufgefallen waren, gab es keine Zeugen. 